\title{
11 The Organization and Functions of the Press Dossier: The Case of Media Discourse on the Environment in Portugal
}

\section{Rui Ramos}

\section{INTRODUCTION ${ }^{\mathrm{I}}$}

This study aims to analyze and explain the macrotextual organization and the most relevant pragmatic-communicative dimensions of a dossier from a daily newspaper in the Portuguese press on the theme of climate change. The study therefore is placed within the theoretical framework of Discourse Analysis, or more precisely the interface of textual genre studies (focusing in particular on press discourse) and Linguistic Pragmatics.

The selected corpus is composed of texts from the November 30th, 1997 edition of Público, a recognised daily newspaper in the contemporary Portuguese press. This edition came out the day before the conference for the negotiation and signing of what would become known as the Kyoto Protocol. The conference was called to set limits and calendars for reducing the emission of gases that lead to the greenhouse effect and to climate change, and was therefore a moment of great social and political importance, both nationally and worldwide.

The choice of texts was dictated by their internal configuration and social function. The discussion of environmental issues commonly appears in the form of many different textual types and genres: among restricted groups of speakers or through public opinion forums; in private circles-family, professional and institutional; and between the young and old, and between men and women. The intention of the various texts may be descriptive, instrumental or combative. But not all of them manifest the relevant characteristics for analysis in the framework of this study. Those chosen for the purpose of this case study take the form of "publicly dominant discourse[s]" (J1ung, 2001, p. 271). These are texts/extended discourses understood as structured and delimited sequences of enunciations constituting a whole, in which the relationship between individuals and the context is publicly defined (namely, in the media). These discourses contribute to the interdiscursive flux of everyday verbal exchanges; providing the concepts, the terminology, the organizational modes, and, above all, creating the real. 


\section{THE DOSSIER UNIT}

The dossier is a common designation in the journalistic sphere and in the context of linguistic analysis of press discourse. Charaudeau2 (1997) describes it as a collection of articles aimed at clarifying a question, as much from the point of view of the facts as from the commentaries included. This description underlines the heterogenic composition of the dossier with the suggestion of the cross-over between the pragmatic dimensions of the texts and the aspects of its sequential organization. Charaudeau approaches the dossier as a whole in recognition of its significance as a trans-textual unit: the dossier typically includes some parts (texts) that are more closely related to information discourse and others that are closer to opinion discourse; some texts are more neutral and others more personally informed; some organize themselves according to narrative models ${ }^{2}$, and others according to argumentative, explicative, descriptive, or dialogued mod$\mathrm{els}^{3}$.

Beacco5 (1992) designates such texts in a dossier as the main text and satellite text $(s)$, thus clearly establishing the hierarchical and complementary nature that characterizes them. He affirms that the former usually performs a descriptive/ narrative function, while the other(s) assume an explicative/interpretative function.

The main text occupies a central position in the dossier's configuration, introducing the topic in question or referring to the core event, positioning itself as the point of reference for the remaining texts and presenting the information judged more relevant, by either the voice of the journalist or that (those) of the protagonist(s). Given that this type of text can be classified as reportage, it would be reasonable to expect the strong descriptive element which is characteristic of this discursive genre ${ }^{4}$. However, authors such as Revaz (1997) defend that reportage is typically narrative with the double mission of informing and explaining.

The satellite texts are complementary to the main text, providing technical information, defining the contours of specific parts of the problems, and offering background elements for an understanding of the central question discussed in the dossier. It is also the function of the satellite texts to create the effect of the real by providing the small details which may seem superfluous, but which in fact provide the general report with the necessary credibility. These details form the background for the development of the core event by registering it in a succession of happenings, or by associating it with other similar ones that happened in the past, or by evoking parallel histories. In the case of dossiers that deal with the core events in environmental issues, it is noticeable that the evoked voices are frequently those of the victims; however, 
specialists or representatives of different interests are also commonly evoked ${ }^{5}$. Finally, the satellite texts also work to construct a background or commentary for the explanation of certain phenomena, which is didactic in character ${ }^{6}$.

It should be noted that there is a collection of other texts with different functions in the journalistic economy and in the mechanism of opening interaction with the reader. They are probably less relevant to the informative content of each dossier, but of real importance in the construction of the newspaper and in the appellative dimension of journalistic treatment. Adam (1997b) classifies them within the peritext ${ }^{7}$, which is organized in the following way:

(a) at the level of the newspaper:

i. name of newspaper;

ii. indication section

(b) at the level of the article:

i. verbal: headline, subtitle, presentation paragraph, internal titles;

ii. iconographic: illustrations, captions.

It must be highlighted that these elements of the peritext have an effective distance from the journalistic texts they appear beside because they are characteristically not dependent on the author of those texts, but instead on "the editorship" (Adam, 1997b, p. 5), with the peritext thus having a different enunciative origin to the articles.

Charaudeau defines what he calls "la titraille" (1997, p. 220) (headlines, subtitles, leads), as an independent discursive genre that, together with the other elements of the graphical organization of the paper (first page, sections, photographs, graphics, tables, columns, etc.), responds to the newspaper's demands for visibility and together they play a triple role: phatic, by contact with the reader; epiphanic, by announcing the news; and synoptic, by orientating the visual path of the reader in the informative space of the newspaper.

In this way, these texts constitute an independent group, which bring other enunciators into the communicative media space. These enunciators are simultaneously readers/receptors of the journalistic articles and writers/producers of the modalized word and highly operative in the effort to capture the attention of the newspaper's addressee.

From the point of view of its communicative functioning, the dossier, in its whole, should respond in particular to two of the four demands that Adam (1997a) identifies in the way the press works: legibility and intelligibility ${ }^{8}$.

The former obliges the written media to report the events taking place in the 
social sphere as clearly as possible, turning the raw event ${ }^{9}$ into a media event, using textual forms such as informative articles, as well as short articles and other essentially expository texts; it also leads them towards an objectified enunciation (Moirand, 1999).

This study pinpoints three separate instances in the configuration of the media event: the reported event, which helps in the construction of a thematic space, and which is a result of the (essentially informative) mediatic treatment of the points of interest; the commentary of the event, or the construction of a problematized space; and the ensuing event, corresponding to the construction of a public debate space outside the media.

The demand for intelligibility refers primarily to the commentary produced from the facts or declarations on the reported event, which find their most prototypical concretization in the textual forms (genres) of the editorials, chronicles, analyses or commentaries.

Having looked at the design of the dossier unit and its respective explanation/ exemplification, it should be noted that the texts that constitute this precise grouping do not all present the same interests or the same internal structure. In order to understand how they are characterized, there now follows an analysis of some of the more salient aspects of the dossier which is the particular focus of this study.

\section{THE CORPUS}

The transtextual organization of the dossier under analysis (see annexes) is structured as follows: on the first page, a high impact title, with a photograph (Text 1); inside the newspaper, a group of seven texts, occupying its first pages (up to page six). There is an opening article, beginning on page two and continuing on page three. This text is complemented, for the purposes of scientific interest, by various others texts, written either by the same journalist, by a scientist or issuing from news agencies; then comes an opinion article. Finally, there is also a map and some information quantified in different graphics and presented schematically.

Even if the essentially iconic texts are excluded from the analysis and the analysis itself is restricted to those texts of (almost) exclusively linguistic formulation, these articles, as their simple enumeration allows us to suppose, present an obvious typological heterogeneity. In some cases, they show an equally notable composite heterogeneity (at the level of the sequential organization of each text).

The main text (Text 2) reveals the starting point of the event. Its textual organization is controlled by the narrative structure, but argumentative and explica- 
tive sequences can also be identified.

The first segment of the text is essentially a descriptive sequence, with the identifiable elements serving to position it temporally and referentially; this segment also reveals the aspectualisation of the text, according to the perspective the speaker adopts and the evaluation he makes in characterizing the overall scenario-not only as regards the actual negotiations, but equally as regards the fundamental questions of climate change. It incorporates argumentative dimensions and makes use of a regressive order between the arguments and the conclusions, beginning with a lapidary phrase which is later justified (definitively in the body of the text), making it more closely related to the model of discourse authorized by Science, with a demonstration of affirmations founded on an observation of the facts:

(1) It will be a battle against egoism. In Kyoto, starting tomorrow, the countries of the world will be judged by their willingness to prevent life on Earth collapsing under climate change. Not one of them wishes to abdicate their economic development. But the climate cannot wait. Portugal knows this, as do many other countries. Floods have brought chaos and pain, and people from Alentejo are already well aware of what it will be like to live in a dry and arid future. The Mediterranean is on the path to disaster, a foreseen catastrophe that was ignored by many. For years, the scientists have been sending out warnings, but recently, they issued their full condemnation of Man as the guilty party. We cannot postpone any longer. Nature simply cannot adapt to such drastic changes. This is not a question of alarmism, fundamentalism or any other isms. It is a question of survival. (Text 2)

The argument for the interpretation of the negotiations as a "struggle against egoism" is developed in later segments, where the desire for "economic development" of some is set up in opposition to the sustainability of life on Earth, at present at risk from "collapsing under climate change." In the same way, the confrontation between the opposing affirmations "Not one of them wishes to abdicate their economical development" and "But the climate cannot wait," linked by the connector of argumentative opposition "but," implies the conclusion that the second affirmation will prevail.

It should be noted that the argumentation herein developed does not begin from zero: there is a recurrent doxa, which is implicitly evoked in all discussions on the topic; this doxa is present in all social discourse from contemporary western societies, and is moreover so well recognised by the citizens of these societies 
that they have come to paraphrase it as "in the present models, economic development and protection of the environment are incompatible." This doxa is not generally disputed, but the multiple arguments which are evoked in association with it tend to result in divergent conclusions.

Nevertheless, the speaker is clearly aware that this can be understood as one more cry in defense of the environment, and that the listener may be displeased by such banalisation, under the facile label of just another ism. He recognizes it, but erases it, by anticipating this reaction and dramatizing the discourse to the limit: this, he contends, is a question of "survival." And models of development must be changed now before it is too late, "because Nature simply cannot adapt to such drastic changes." This is an argument that sustains the conclusion ultimately advanced, and explains the relation between the two (as identified by the explicative/argumentative connector "because").

It is therefore legitimate to describe this introductive segment as being dominated by a descriptive structure with some typical elements and, especially, with contextual indicators that determine this expectation. It must be pointed out that there is also a complex argumentative dimension developed throughout the descriptive and explicative segments, which, from the very beginning, heralds the heterogeneous structure that characterizes the text.

The same sequential organization runs through the whole text. Its first two paragraphs define the starting point of the event (the beginning of the negotiations), aspects of contextualization (the divergence between positions, particularly between the "rich and poor" is presented as "a given"), and its implications (either a treaty is signed or life on Earth "will be seriously threatened"). What follows, in the third paragraph, is an analeptic movement introducing a historical context (which has already been introduced at the beginning of the second paragraph, affirming that "climate change is the big question now at the end of this century"), which reinvokes the relation between policy makers and scientists regarding the importance of recognising the problem of climate change.

Next, various explicative segments appear. A brief illustration of the greenhouse effect is given, essentially in the form of imminent and tangible repercussions (right from the presentation paragraph all the way through). But an actual explanation of the phenomenon, given in more technical language, and approached in more depth, will appear only in Text 8 , which is clearly divulgative in intention. In conjunction with the explicative segments, Text 8 underlines the incipient divulgative vocation of the main text, but it also testifies to a complementary relationship between the main text and the satellite texts, and a strong connection between the elements that form the dossier. This text refers to "climate change," or "the gas emissions that lead to the greenhouse effect," but other technical terms such as "carbon dioxide," "methane," "nitric oxide," "pler- 
fluorcarbons," etc., including the chemical symbols or signs that identify them, only appear in the satellite texts.

In the same way, the main text points out some of the real consequences of the phenomenon, those within the scope of the readers' experience; but it is the task of Text 3 to develop the topic, evoking, to that effect, the voice of a "scientist" from the "Lisbon University Faculty of Sciences," and introducing other strong arguments voiced by various different sources.

There is also a segment that definitively explains the initial affirmation of the speaker, "It will be a struggle against egoism," although this explanation will only finally be completed at the very end of the article:

(2) But national egocentrisms continue to prevail. The principal guilty party for the gas emissions creating the greenhouse effect does not want to sacrifice a penny of its actual economy to prevent the catastrophe. The USA arrived in Japan with an extremely modest proposal: to stabilize the emissions over the next 15 years at the levels registered in 1990. To this end, they demanded that the poorer countries, which aspired to a better life but at present were doing little to contribute to the problem of climate change, should also limit their emissions. The argument is valid- "they should not make the same mistakes as us" - but it will not be easily accepted by those who already have so little to lose. The scission has been created. (Text 2)

The opening statement of the paragraph, which re-emphasizes the initial affirmation of the article, is explained/justified in the propositions that follow, particularly regarding the standpoint of the USA. In this way, a subtle change is worked: from the "national egocentrisms" introduced initially, the discourse slides towards an explanation of only one of these egocentrisms, the North American. The US is thus the major opponent of those who "already have so little to lose," which is to say, the poorer countries—and, as was previously mentioned, this is a powerful artifice in the construction of a scenario that clearly privileges one of the sides in the conflict (notice the contrast between the "wellbeing" of the Americans and the scenario of "catastrophe").

What follows are three descriptive paragraphs tracing the positions of each country or group of countries. There are, again, explicative segments, such as the following:

(3) Europe has decided to take a leading role and put an audacious proposal on the table, but it is one that will inevitably be rejected. 
Even before the meeting, the Japanese press published articles on the willingness of the Union to reduce its proposal for a $15 \%$ reduction in emissions to $10 \%$, to be achieved by the year 2010 , a tactical manuever designed to make the other countries accept the proposal. (Text 2)

The evaluation-conclusion is not explicitly present in this segment, but instead in the final paragraph of the text. This, in fact, takes the form of a conclusion of an argumentation that has been developed throughout the article: on the one hand, the problem is global and demands "global solutions" (treaties between all the countries in the world); on the other hand, each country has to "assume its responsibilities," without egoisms.

In this way, the composite heterogeneity of this main text is clearly established; likewise its descriptive functions (of a state of things) and technical divulgations to a wide public are also demonstrated. The main text's vocation in the economy of the dossier's is to build a complete scenario: this includes the central action and the main characters, whose motivations, characterization and movements should be summarily drawn, thus leaving space for complementary information, evaluation, background scenery, props and the extras brought on in the satellite texts.

It was mentioned previously that Text 8 in this dossier is characterized by divulgative intentions. Text 4 can be characterized in the same terms:

(4) This phenomenon is called "greenhouse effect" because it is exactly this that provides the heat felt in greenhouses used in agriculture. Why is it that the light (and the heat) can pass through the atmosphere when they come from space, and yet cannot pass through when they are reflected up from the earth's surface? Because, after having struck the land or the sea, the rays of light suffer an alteration in their wavelength (in their colour) and the atmosphere is less transparent to this new light." (Text 4)

\section{(5) What is the greenhouse effect?}

Life on Earth is hugely dependent on the greenhouse effect. The carbon dioxide, ...

\section{What is climate change?}

Because the heat remains trapped next to the Earth, the Climate automatically changes....

\section{How do we release the gases with a greenhouse effect?}


The principal gases with a greenhouse effect are carbon dioxide $\left(\mathrm{CO}_{2}\right) \ldots($ Text 8$)$

Various segments of these texts of scientific divulgation are constructed by imitating, as closely as possible, the precise interaction between speaker and audience: this is the case of Texts 4 and 8, the latter being organized as "Questions and answers on climate change" (this being its actual title) and taking up an interactional dialogue comprised of the didactic texts, or of the many segments with interrogative structures, reproducing the organization of the multiparty texts and the shared intervention of the audience in the definition of the discursive model.

The explicative segments are dominant, almost exclusive in some texts (as segments (4) and (5) show); their aim is to be accessible to the common reader, who is unspecialized or uninitiated in these matters and without the scientific fundaments which would allow him to understand the questions and take an informed position, explicitly activating the scheme of the explicative sequence as Adam (1997a) describes it.

Regarding the definition of the contours of discourse on the environment, it is possible to point out how some texts work as a mechanism of adaptation/ re-contextualization of the scientific articles originally produced within the parameters and procedures of scientific communication (that is to say, in restricted communities, already initiated in the subject matter and dependent on specific rules). In this way, Text 4 is an adaptation of a scientific article that originally appeared in Science magazine, published nine days before (November 11 ${ }^{\text {th }}, 1997$ ); Text 6, composed essentially of maps and scientific data from the same dossier, is co-authored by the Hadley Centre ${ }^{10}$, a research unit on climate change at the British Institute of Meteorology.

What is first identified then is the sudden entry of the discourse of Science into the discourse on the environment, manifested by the identification of sources and authors of articles. Likewise, there is an alteration in the original discourses through the presence of the "adaptation" to which they were subjected in order to support and fulfill the different functions performed in the newspaper. Thus, they take the form of an explicit intertextual dialogism (M2oirand, 1999).

On the other hand, the inclusion of these texts in the dossier reinforces its definition as a heterogenic construction. Besides the already mentioned text types, texts with a very strong iconic component (maps and graphics) now also appear.

Text 3, dominated by descriptive and explicative structures, characterizes Portugal's situation in the face of the risks of climate change, underlining the precise negative consequences. The macro-proposition of the topic anchor, pointed out by Adam (1997a) as a characteristic of the descriptive sequences ${ }^{11}$, develops in 
the first paragraph of the text:

(6) Being a coastal country is rapidly becoming a disadvantage. With a coastline of 800 kilometres, Portugal will be one of the first to suffer from one of the major consequences of climate change: the rising of the sea level. But the problems do not end there. The lack of drinking water will be acutely felt, desertification will advance in the interior and the floods, downpours and storms will come to stay. (Text 3)

The macro-proposition of aspectualisation is immediately identified in this first paragraph as having an indisputable orientation: the dramatization of the present and future realities (by their enumeration, but also by the characterisation of the rising sea levels as one of the "problems") will work as a strong argument for justifying the necessity of an international treaty on emissions.

But the macro-proposition of relation, by which are established metonymic relations with the global problem, is also found throughout the whole text. This begins in this initial paragraph until the second part of the article, separated by an internal title ("The Disadvantages of South Europe") which explicitly introduces the Portuguese problem (and the countries from the Mediterranean basin) into the global picture. In this way, the specific national circumstances are inscribed in a larger scenario- that of global climate change. Thus, the internal manifestations of the problem appear as a mirror image of that which affects the entire world.

The explicative function is important in bringing home the actual significance, in experimental consequences, of a problem that is invisible to the common citizen. This mechanism of reification is also patent in the first paragraph of the text, but takes no less recognisable forms in the fifth paragraph with precise quantifications, technical terminology and demonstration of palpable consequences, while evoking the authorized voice of Science:

(7) What is certain is that what is happening in this country is exactly in line with what has been observed and predicted on a global scale. The 1995 report from the Intergovernmental Panel on Climate Change (IPCC), comprising a large group of scientists and technicians from the whole world, predicts that the South of Europe will experience a temperature increase of between 1.5 and 4.5 degrees centigrade if the emissions of carbon dioxide double. Furthermore, the report shows that there will be a decrease in precipitation in the whole of the Mediterranean and, therefore, a decrease in river volumes. (Texto 3 ) 
Once again, the final paragraphs reveal the argumentative orientation behind this descriptive and explicative construction, urging study and action "in anticipation"- even though the rhetorical question that closes the article suggests that there are doubts concerning Portugal's capacity to respond favourably to this demand, a fact that increases the general climate of unavoidable catastrophe.

(8) In the face of this evidence, there are only two options: do nothing, hoping that those most responsible for the carbon dioxide emissions agree to reduce pollution at the Kyoto Summit-Portugal will not have to make great sacrifices to reduce its emissions because the national contribution stands at about $1.5 \%$ within the Union, and, according to the national report for Kyoto, it could still increase this by $40 \%$ - or begin to prepare the country to be able to face the increase in frequency of these floods, storms, and the lack of water. The key to success is to study the question and act in advance. But, would the country be capable of such planning? (Text 3)

The suggestion of the possibility of choice in the penultimate paragraph is rhetorical, delimitating a possibility that is presented as convenient in the short term but unacceptable because of its mid- to long-term consequences, a fact which naturally orientates the reading of the text in only one direction.

Essentially, these segments concisely recover the whole scenario laid out throughout the text and present it as undeniable, paraphrasing it as "the evidence," in a final movement of authorization of the previous discourse. They apparently admit two possible directions for Portugal.

The first direction corresponds to the "do nothing" and in general terms, again takes up the not-guilty and convenient arguments of some of the politicians responsible, grouped together under the "national report for Kyoto" umbrella. This is all in keeping with a common sentiment held by the Portuguese, which implicitly evokes Lusitanian smallness-geographically, economically, politically, and, as is to be expected, in terms of responsibility for the gas emissions that lead to the greenhouse effect. As in many other aspects of community life, the report suggests that the responsibility and onus for change falls on the heads of others.

The second, directly opposite path to follow (as the structure marked by the disjunctive connector "or" shows), will prepare the country to face the environmental catastrophe. This makes the second path inevitable in the case of the first possibility of action not being followed. Thus, this structure is configurated 
with a conditional value: if Portugal and "those most responsible for the carbon dioxide emissions" reduce their emissions, it won't be necessary to prepare the country to face the cataclysm. The cause-effect connection between the emissions and environmental catastrophe is presented as a given, thus avoiding a direct declaration which might (more easily) be refuted by the listener. The text closes with a challenge issued in the form of the rhetorical question at the end. The challenge is strong, in part because of the importance of the questions in play and in part because of the suggestion of failure (or of strong doubt that the speaker seems to feel) marked by the future modal: "would."

Despite being dominated by descriptive and explicative sequential structures, a favorable argumentative line regarding the signing of the Kyoto Treaty runs all the way through Text 3 , thus influencing public opinion to this end.

The opinion article (denominated as "Commentary"), intergrated in the dossier, which also belongs to the group of satellite texts, is dominated by narrative and argumentative sequences (mostly the latter). Here appearing as Text 5, this article is authored by the director of the newspaper and begins with a descriptive structure:

(9) While we go around dazed by reshufflings and other minor episodes here, on the other side of the planet a Summit is being organised which is undoubtedly much more important for our future than the numbers of "Cardinal" Pina Moura or the resurrection of the eternal Veiga Simão. Meanwhile, in Kyoto they will try to invert an evolution that is leading our planet towards catastrophe. (Text 5)

This first paragraph of the text outlines the entire scenario, highlighting the point in discussion: the Kyoto Summit. This is an operation of referential anchorage. A second macro-proposition of aspectualisation runs parallel to this in the form of an evaluation of the state of things, which incorporates equally a movement of convergence and of divergence.

The movement of convergence establishes a link between the speaker and the listener, by the use of "we" in "go around." Furthermore, this use of the first person, which appears in exclusivity in the opinion articles, is witness to the speaker's subjectivity. This subjectivity is indicated by the peritextual elements that perform a preliminary contextualization of the text; the suggested complicity puts the commentator on the side of the reader-or, preferably, the reader on the side of the commentator, sharing his point of view about the state of things being analyzed and commented upon in the article.

The movement of divergence resides in the critique developed by the speaker: 
the Portuguese people "go around dazed by reshufflings and other minor episodes." From the semantics of "go around dazed" comes

- the referred critique but also, by pragmatic implication, a call for a change of behaviour;

- the confrontation, at an implicit level, between the essential and the accessory, with the focus of attention being on the latter to the detriment of the former.

The cross-over of the two previous items results in a call for a change in focus of the Portuguese, which is explicit in the text: the accessory is the "reshufflings (of government) and other minor episodes," while the essential corresponds to "a summit which is undoubtedly much more important for our future" than the mentioned "episodes." In both cases, the adjectives stand out: the first being a comparative of inferiority and the second a comparative of superiority (intensified by the adverb "much"), thus stretching the extreme limits of the scale of values portrayed.

The macro-proposition of relation is also activated by the evocation of what is known by the listener (he who likewise goes around in a daze), as the economic reference to the episodes of Portuguese political life confirm - the "reshufflings" and the other "minor episodes," co-referenced with expressions like "the numbers of "Cardinal" Pina Moura or the resurrection of the eternal Veiga Simão." It is to be noted that this co-referentiality is not explicitly affirmed but rather suggested to the listener. The listener will recognize it in a movement of interpretative cooperation which will only happen if, in fact, there is some kind of sharing of knowledge between the speaker and the listener. This supposition of sharing of universes and encyclopedia makes it evident which profile the journalist idealizes in his readers.

Finally, this descriptive segment is taken up by the actual speaker to fulfill an argumentative function, as can be verified by the connector "meanwhile" at the beginning of the second paragraph, justifying the affirmation produced in the first, in a regressive argumentative order. This justification clarifies the topic indicated at the beginning of the text, making it clear that it's about the summit and not about the "minor episodes" of internal politics. It serves equally for an extreme dramatization, recurrent in the corpus, of the projected "catastrophe" scenario, a scenario that is coherent with the contrast between the essential and accessory mentioned above. This is in agreement with the affirmations of Masuy (1997) on the argumentative dimensions supported by the descriptive segments, that which Adam (1997a) describes as "the heterogeneity of type [dominant sequence $>$ dominated sequence]." 
The text continues with a narrative segment, corresponding to the next paragraph, in which two lines of organization evolve, in parallel and mutually supported; one is temporal and the other argumentative:

(10) At the beginning of the 80s, when the discussions on climate change, the greenhouse effect and global warming first began, there were many who looked disbelievingly at the scientists who placed the blame on human activity. Five years ago, in Rio de Janeiro, at the Eco-92, the amount of scientific proof was already sufficient to take measures-but there was no political will. Now it's no longer possible to ignore the problem. This problem, essentially, puts into question the models of development of the last century and a half in human evolution. Quite simply, the origin of the problem is carbon dioxide, $\mathrm{CO}_{2}$, which industrialized societies produce on a large scale. (Text 5)

The narrative structure is tripartite, with three almost overlapping temporal indicators: "At the beginning of the 80s," "five years ago," and "now."

Besides these, there are further argumentative axes of increasing scientific certainty about the causes of global warming: "there were many who looked disbelievingly at the scientists who placed the blame on human activity," "the amount of scientific proof was already sufficient to take measures," "Now it's no longer possible to ignore the problem."

This temporal and scientific evolution subscribes to the generalized conviction that conceives of scientific progress as an undeniable fact and of contemporary societies as more scientifically and technologically evolved than in the past, in a line of constant and unidirectional progress. However, alongside the recognition of the importance of Science and of technology in occidental societies and in the real life of modern man, coexists the notion of the limits, the fragilities and the blank spaces in Science; it too, just like many other aspects of social life, is the object of doubt and polemic. If the unstoppable march of time goes unquestioned and is therefore difficult to prove, the same is not true of the affirmations of Science. In this way, the association of those two realities offers a greater credibility to its fragile side: the inscription of the growing scientific conviction in the axes of time acquires a growing force of truth. Of course, this effect stems equally, as paradoxical as it may seem, from the confession of doubts, even if distance in time is supplanted by scientific progress (and by the progress of scientific certainty), about the role of human activities in the global warming of the earth's atmosphere. Moreover, the speaker lists a group of facts to offer as testimony to the previous affirmations, in a model of argumentation 
in regressive order. This is an insistent option in the corpus, which ultimately also proves the argumentivity of the affirmations produced.

What has to be underlined at this point is the overlapping of the narrative and argumentative structures, with the supremacy of the pragmatic objectives sought by the latter.

Text 5 also shows indicators of composite heterogeneity into which explicative and argumentative sequences intervene:

(11) The scientific evidence has begun to be imperative: if the gas emissions that lead to the greenhouse effect continue to grow at this rate, within one century we will be traveling by boat in Terreiro do Paço and by camel in the Alentejo, or we will be fighting malaria in the Minho valleys. Is this an exaggeration? Perhaps not. It could all in fact be worse. One of the possibilities that scares the scientists is that warming of the atmosphere could eventually provoke a global change of the maritime currents—a kind of "El Niño" on a global scale - a change capable of totally upending our climates and provoking the complete ruin of agriculture production. At present, no one can foresee this phenomenon, but there is an image that is sometimes used: the elasticity image. In reality, all the studies start from more or less linear models, the same linearity with which elastic is stretched: we can say how far it will stretch depending on the force used. However, none of the models can respond to what would happen if there was a qualitative alteration, that is, if the elastic should break. The same could happen with our climates. (Text 5)

The sequential explicative organizational model starts from an affirmation that is afterwards explained, as is clearly indicated with the marker of reformulation "that is," the segment "a kind of," and also the express reference to the "image" that the speaker constructs to explain a reality not immediately accessible (from his point of view) to the understanding of the listener. However, it can be clearly stated that this segment is not one of scientific explanation. Rather it is one of argumentation; the presentation of all the data and affirmations of the qualified enunciators ("the scientists") confirms the affirmation made in the first of these paragraphs (again, in a regressive argumentative form).

Consequently, this explanation seems to equally sustain the structure and the dominant objective of the text, of the argumentative domain. This dominant objective is revealed in the last paragraph: 
(12) What are the ways out (for the environmental problems)? It's important to continue to study the climatic phenomena and to put pressure on the governments. In spite of everything, the evolution since Eco-92 has been great. (Text 5)

This conclusion of the text concretizes the directive dimension developed in the argumentation and configures the text as circular: the only way out will be to "continue to study the climatic phenomena and to put pressure on the governments." This is the conclusion strategically anticipated from the very beginning by the organisation of the text, in particular by the drawing up of the eventual scenarios of future environmental calamity if the "way out" presented here at the end should be refused. Accordingly, the macro-textual complex in study can be understood as an organization orientated to a make-believe and make-accept (the speaker's points of view) at the service of a make-make (support/demand the study of solutions from the scientific community and put pressure on the policy makers to take favourable decisions from Kyoto), with the composite heterogeneity being subordinate to those dominant pragmatic objectives. From the speaker's point of view, the fact that the Portuguese were going around "dazed" by banalities gives the warning an added urgency. This obvious criticism of the Portuguese, with its implicit call for change, is affirmed at the beginning of the article; the possible response/solution is found at the end.

\section{FINAL REMARKS}

It can be said that, in the same way as this opinion article, the dossier's organization is also circular: from the predominately informative text, to the explicative texts, and finally the opinion text, the facts and arguments evoked by the conflicting parts support the mobilising speech of the newspaper's director. This fact confers a great coherence to the group of texts, which are mobilised in the same ideological orientation and the same perlocutionary objectives. The dossier thus appears as a complex of elements united by a strong connection, which goes beyond the thematic confluence and encounters a new pertinence in the pragmatic objectives sought. 


\section{APPENDIX A: IMAGES}

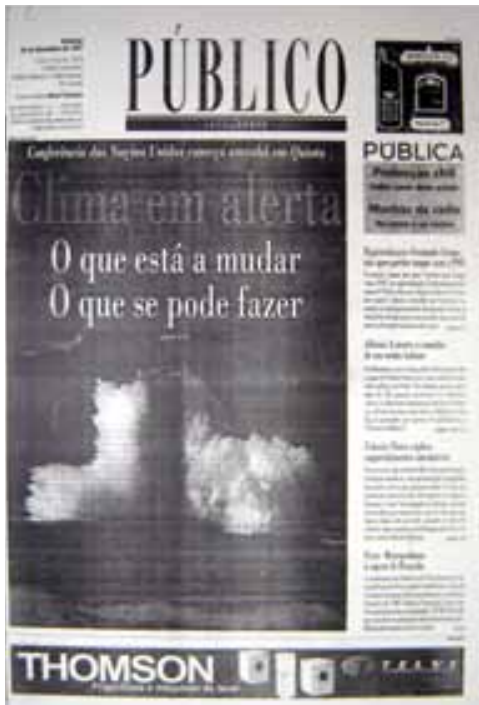

FIGURE 1: TEXT 1

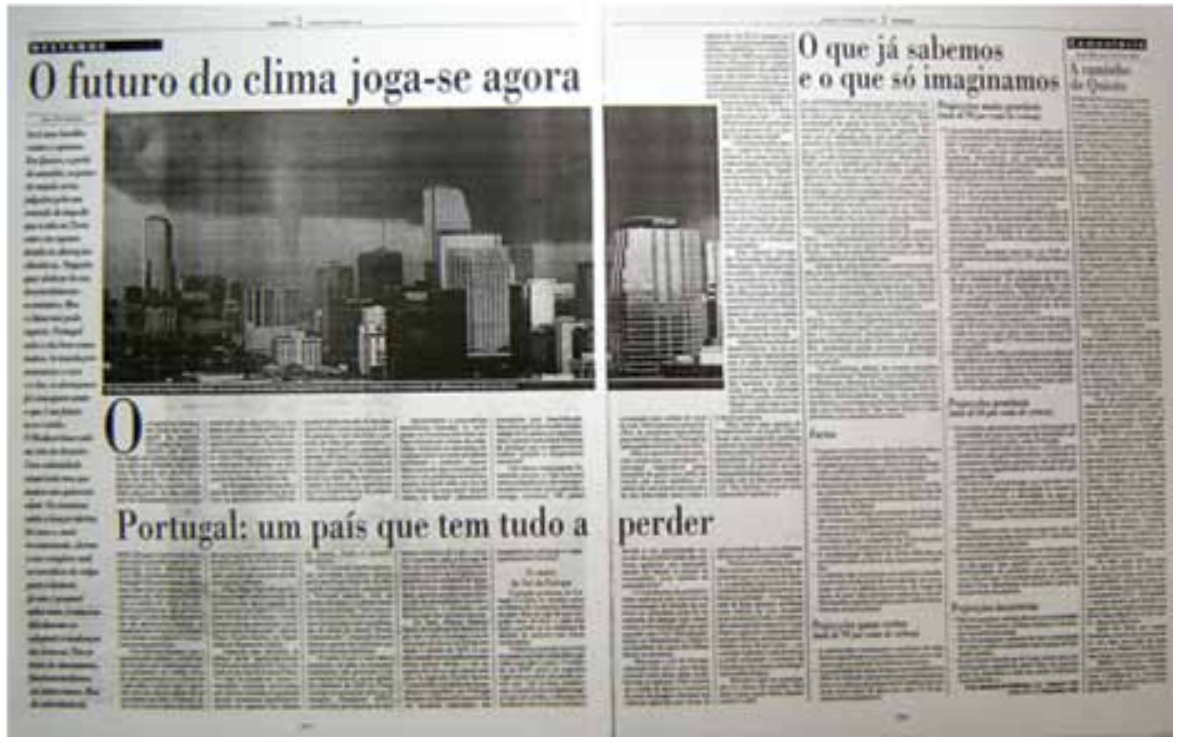

FIGURE 2: TEXTS 2-5 


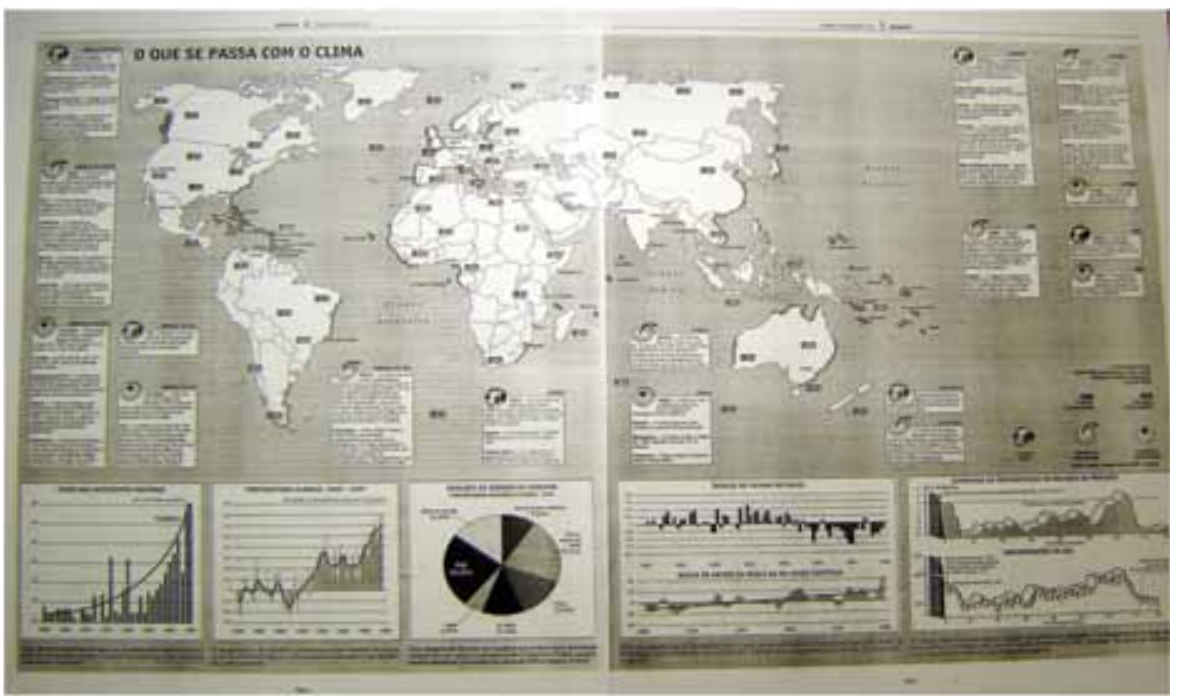

FIGURE 3: TEXT 6

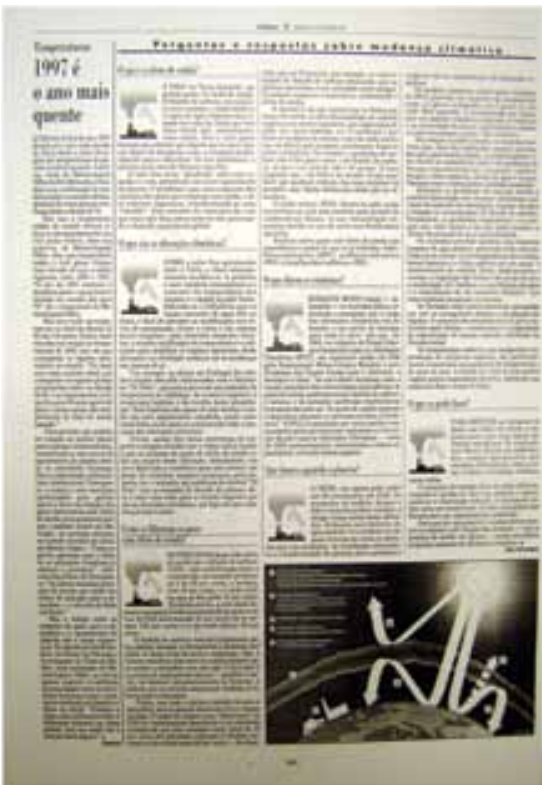

FIGURE 4: TEXTS 7 AND 8 
APPENDIX B: IDENTIFICATION OF THE CORPUS

\begin{tabular}{|c|c|l|}
\hline TEXT & \multicolumn{1}{|l|}{ PAGE } & TITLE \\
\hline 1 & 1 & Climate in danger. What is changing. What can we do. \\
\hline 2 & $2-3$ & The future of the climate is at stake now \\
\hline 3 & $2-3$ & Portugal: a country that has everything to lose \\
\hline 4 & 3 & What we already know and what we only imagine \\
\hline 5 & 3 & The way of Kyoto \\
\hline 6 & $4-5$ & What is happening to the climate \\
\hline 7 & 6 & 1997 is the hottest year \\
\hline 8 & 6 & Questions and answers on climate change \\
\hline
\end{tabular}

\section{NOTES}

${ }^{1}$ This article is the result of research carried out in the ambit of the project "The politics of climate change: discourses and representations", financed by the Portuguese Foundation for Science and Technology. (POCTI/COM/56973/2004)

${ }^{2}$ See Adam (1997a).

${ }^{3}$ Journalistic manuals commonly divide the identifiable genres in the written media into information and commentary, based on the following criteria: (a) semantic (the topic); (b) argumentative and pragmatic (the illocutionary objective- to inform and explain); and (c) enunciative (position of the journalist to his discourse or his sources). But this organisation is not consensual and, according to Adam (1997b), it corresponds more to the position of the enunciator regarding the informational contents than to a real division of genres. In this, the position of Moirand (1999) coincides with Adam when she refers to genres of subjectivized enunciation as presenting indicators of either explicit or identifiable subjectivity, and which are defined as such (e.g., opinion, editorial, etc.) and the genres of objectivized enunciation as being without indicators of the speaker's subjectivity or with these signs significantly hidden (e.g., news, reportage, brief, scientific article, etc.).

${ }^{4}$ See Masuy (1997).

${ }^{5}$ See Ramos (2005).

${ }^{6}$ See Cicurel (1994) and Adam (1997b).

${ }^{7}$ Adam (1997b) criticises the notion of genre sometimes being applied to the title or lead (which are nothing if not peritextual units) of journalistic texts. The 
same consideration is extended to the operation of reformulation of earlier texts and communications emitted by the news agencies. In this case, we are dealing with criteria external to the textual material, which depend only on conditions of production.

${ }^{8}$ The third and fourth of these demands are visibility and dramatization, respectively.

${ }^{9}$ See Charaudeau (1997).

${ }^{10}$ The Hadley Centre for Climate Prediction and Research.

${ }^{11}$ According to Adam (1997a), the remaining macro-propositions are aspectualisation, relation and organisation according to sub-topics.

\section{REFERENCES}

Adam, J.-M. (1997a). Les textes: Types et prototypes. Récit, description, argumentation, explication et dialogue. Paris: Nathan.

Adam, J.-M. (1997b). Unités rédactionnelles et genres discursifs: Cadre général pour une approche de la presse écrite. Pratiques, 94, 3-18.

Beacco, J.-C. (1992). L'explication d'orientation encyclopédique: Remarques sur un régime discursif. Les Carnets du CEDISCOR, 1, 33-54.

Charaudeau, P. (1997). Le discours d'information médiatique: La construction du miroir social. Paris: Nathan.

Cicurel, F. (1994). Les scénarios d'information dans la presse quotidienne. Le Français dans le Monde, Numéro Spécial Recherches et Applications: Médias Faits et Effets, 91-102.

Jung, M. (2001). Ecological criticism of language. In A. Fill \& P. Mühlhäusler (Eds.), The ecolinguistics reader. Language, ecology and environment (pp. 270285). London: Continuum.

Masuy, C. (1997). Description et hypotypose dans l'écriture journalistique de l'ambiance. Pratiques, 94, 35-48.

Moirand, S. (1999). Les indices dialogiques de contextualisation dans la presse ordinaire. Cahiers de Praxématique, 33, 145-184.

Ramos, R. (2006). Aspectos do discurso do ambientalismo nos media escritos. Unpublished doctoral thesis, University of Porto, Porto, Portugal.

Revaz, F. (1997). Le récit dans la presse écrite. Pratiques, 94, 19-33. 